\title{
MONITORAMENTO IN SITU, EM TEMPO REAL DA POLIMERIZACAO EM MINIEMULSAO DE ACRILAMIDA UTILIZANDO A ESPECTROSCOPIA NIR.
}

\author{
M.M.E.COLMÁN ${ }^{2}$, D.L.CHICOMA ${ }^{2}$, R. GIUDICI ${ }^{2}$, P.H.H.ARAÚJO ${ }^{1}$, C. SAYER ${ }^{1 *}$ \\ ${ }^{1}$ Universidade Federal de Santa Catarina, Departamento de Engenharia Química e Engenharia de \\ Alimentos \\ ${ }^{2}$ Universidade de São Paulo, Escola Politécnica, Departamento de Engenharia Química. \\ E-mail para contato: csayer@enq.ufsc.br
}

\begin{abstract}
In this work, the ability of on-line NIR spectroscopy for the prediction of the evolution of monomer concentration, conversion and average particle diameter in acrylamide inverse miniemulsion polymerization was evaluated. The spectral ranges were chosen as those representing the decrease in concentration of monomer and an increase in the base line shift indicated that NIR spectra were affected by particle size. Multivariate partial least squares calibration models were developed to relate NIR spectra collected by the immersion probe with off-line conversion and polymer particle size data. Results showed good agreement between off-line data and values predicted by the NIR calibration models and these latter were also able to detect different types of operational disturbances. These results indicate that it is possible to monitor variables of interest during acrylamide inverse miniemulsion polymerizations.
\end{abstract}

\section{INTRODUÇÃO}

Hydrophilic polymers have numerous applications, as flocculants, adhesives and viscosity control agent for petroleum, chemicals for the paper industry and mining processes, that represent a market that drives about a billion dollars each year (Ullmann's, 2000 and Qi et al., 2009).

Acrylamide polymerization is characterized by a high ratio between propagation and termination rate coefficients, resulting in polymers with high molecular weights, high viscosity, high of heat release rate, leading to poor mixing and heat transfer when operated in industrial scale (Lovell et al., 1997). The compartmentalization of the radicals in the submicron sized particles provides some advantages of emulsion and miniemulsion polymerization techniques, such as higher reaction rate and higher molecular weights. In addition, the resulting product is a dispersion of submicrometric polymer particles and there are fewer problems due to heat transfer or mixing during the polymerization since the viscosity of the continuous phase is low. The dispersed phase (submicrometric droplets) of inverse miniemulsion polymerization is composed of a polar monomer, water and a costabilizer (lipophobe) to minimize diffusional degradation, also known as Ostwald Rippening. And the continuous phase, in which the droplets are dispersed, contains the nonionic surfactant, to retard coalescence (Landfester, 


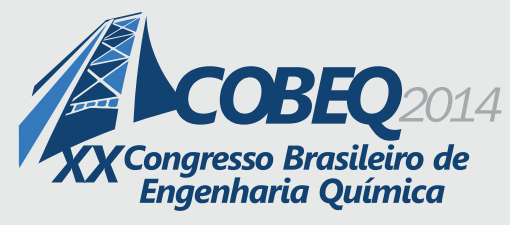

19 a 22 de outubro de 2014

Florianópolis/SC

2000). Since monomer droplets/particles are the main polymerization locus and due to their high superficial area, the initiator may the either soluble in the dispersed phase (Capek, 2003; Qi et al., 2007; Kobitskaya et al., 2010) or in the continuous phase (Qi et al., 2007; Kobitskaya et al., 2010; Romio et al., 2013) or in both phases as in the case of the redox initiation system used by Blagodatskikh et al. (2006).

NIR spectroscopy has the advantages of ease of handling, and rapid measurements, the ability to monitor simultaneously the different polymer properties (Reis et al., 2004 a, b; Chicoma et al., 2010), as well as the possibility of using a multiplexer system. The NIR region comprises the visible region of $12,500 \mathrm{~cm}^{-1}$ to $4000 \mathrm{~cm}^{-1}$ and mainly contains overtones and combination bands (Patnaik et al., 2004). And the elaboration of multivariate calibration models is required to relate NIR spectra with properties of interest (Santos et al., 2005; Reis et al., 2005, 2007, Silva et al., 2011), such as monomer concentration, conversion, and droplet/particle diameters throughout the reactions.

In the present work the feasibility of using NIR spectroscopy for online monitoring of changes in monomer concentration, conversion and average diameter particle of inverse acrylamide miniemulsion polymerizations conducted at different temperatures and with different types of surfactants and initiators (oil- or water soluble) was verified. Polymerization reactions carried out in the batch mode were used for the development and validation of NIR calibration models.

\section{EXPERIMENTAL}

The continuous lipophilic phase of the inverse miniemulsion was prepared by dissolving the surfactant, polyglycerol polyricinoleate (PGPR) or SPAN 60, in cyclohexane. In sequence, the monomer, acrylamide (AAm), and the costablizers, sodium chloride $(\mathrm{NaCl})$ and polyvinylpyrrolidone (PVP) were dissolved in water to prepare the aqueous phase. Two types of initiators were used, the water-soluble potassium persulfate (KPS) or the oil soluble 2,2'-azo-bis-isobutironitrile (AIBN). The former was dissolved in the aqueous solution, while the latter was dissolved in a small amount cyclohexane and added to the reaction medium after the miniemulsification. Both phases were mixed and magnetically stirred for 30 min forming a coarse emulsion. When the aqueous phase initiator was used this step was performed at $10^{\circ} \mathrm{C}$ to prevent the onset of the reaction during miniemulsification. A Ultra Turrax Digital T25 homogenizer (5 min at $20000 \mathrm{rpm}$ in an ice-water bath) was used to prepare the miniemulsion. The inverse miniemulsion was then transferred to a $250 \mathrm{~mL}$ jacketed reactor with a magnetic stirring bar, NIR immersion probe, thermometer and stirred under a nitrogen stream to avoid inhibition of the polymerization process by the presence of oxygen.

Latex characterization: Conversion was determined by gravimetry based on the following procedure: samples were collected from the reactor and precipitated in excess of chilled acetone containing $0.1 \mathrm{wt} \%$ of hydroquinone, and then separated by centrifugation. The precipitate was dried at $60^{\circ} \mathrm{C}$ to remove residual acetone, ciclohexane and water. The conversion was calculated as the ratio between the mass of dry polymer and the amount of monomer that the sample taken from the reactor should contain if no reaction occurred. When PGPR, surfactant with double bonds, was used, the procedure described by Hunkeler (1990) was followed to calculate conversion. The intensity average particle diameter was measured by dynamic light scattering technique (DLS, Beckmann Coulter N4 Plus) diluting the samples in cyclohexane. Table 1 shows the recipe of the polymerizations. The 


\section{9 a 22 de outubro de 2014 \\ Florianópolis/SC}

reactions $\mathrm{M} 1\left(63^{\circ} \mathrm{C}\right), \mathrm{M} 2\left(60^{\circ} \mathrm{C}\right), \mathrm{M} 4\left(65^{\circ} \mathrm{C}\right), \mathrm{M} 5\left(55^{\circ} \mathrm{C}\right), \mathrm{M} 6\left(55^{\circ} \mathrm{C}\right.$, increase of reaction temperature to $65^{\circ} \mathrm{C}$ after $180 \mathrm{~min}$ of reaction), were used $2 \%$ of KPS and PGPR as surfactant, and the reactions $\mathrm{M} 3\left(65^{\circ} \mathrm{C}\right)$, and $\mathrm{M} 8\left(60^{\circ} \mathrm{C}\right.$, addition of $50 \mathrm{wt} \%$ of the reaction medium after $70 \mathrm{~min}$ of reaction) were used $1 \%$ of KPS, that last with Span 60 and in the M3 was used PGPR as surfactant.

Table 1. Recipe used in the acrylamide inverse miniemulsion polymerizations.

\begin{tabular}{|c|c|c|}
\hline Phase & Reagents (g) & Mass (g) \\
\hline \multirow{4}{*}{ Dispersed } & Water & 15.0 \\
\cline { 2 - 3 } & Acrylamide $^{\mathrm{T}}$ & 11.2 \\
\cline { 2 - 3 } & $\mathrm{NaCl}^{\mathrm{a}}$ & 2.920 \\
\cline { 2 - 3 } & $\mathrm{PVP}$ & 0.94 \\
& $\mathrm{KPS}$ & variable \\
\hline \multirow{3}{*}{ Continuous } & Cyclohexane & 101.2 \\
\cline { 2 - 3 } & PGPR or SPAN 60 & 6.02 \\
& AIBN & variable \\
\hline
\end{tabular}

Online Monitoring: NIR spectra were collected online with an IFS 28/N Bruker spectrometer, equipped with a quartz bean splitter, using a probe (Hellma 661.622 NIR, with a transflection system and overall light path equal to $2 \mathrm{~mm}$ ) immersed into the reaction medium. Spectra acquisition and processing were developed using the OPUS software package. Gravimetric and DLS data were used as reference data in the multivariate partial least squares (PLS) calibration models.

\section{RESULTS AND DISCUSSION}

The second derivative with 25 points (smoothing) using the Savitzky - Golay method was chosen as spectra pre-treatment technique due to its good results for this type of heterogeneous system (Vieira et al., 2002; Chicoma, 2009). The calibration set of reactions, composed of polymerizations $\mathrm{M}$ 1, M 2 and M 3, was chosen to cover a wide range of conversion values.

The best internal cross-validation results in terms of coefficient of determination $\left(\mathrm{R}^{2}=99.4\right)$ and root mean square error of cross validation (RMSECV) were obtained for the first region overtone $\left(5855-6250 \mathrm{~cm}^{-1}\right)$ with seven principal components.

Figure 1 compares NIR and gravimetric results of residual acrylamide concentration and conversion for the inverse miniemulsion polymerizations that were not used in the calibration model. All reactions conducted with the aqueous phase initiator KPS, that was added to the dispersed phase prior to the miniemulsification procedure, show an initial conversion around $17 \%$, followed by an induction time during the first minutes of reaction due to the presence of traces of oxygen (polymerization inhibitor). The induction time occurred for all reactions (with KPS and AIBN) as the oxygen enters the reaction medium during the emulsification and homogenization (with Ultra Turrax) steps. The eventual presence of other impurities may also contribute to this induction time (Capek, 2010; Qi 2007). Though, initial induction times are usually not desired, but the ability to predict correctly the end of the induction time is a desired feature of process monitoring. After this initial induction time, reaction rate was very high due to the high propagation coefficient value of 
acrylamide, $\mathrm{kp}=4.3 \times 10^{4} \mathrm{~L} \cdot \mathrm{mol}^{-1} \mathrm{~s}^{-1}$ at $60^{\circ} \mathrm{C}(\mathrm{Qi}, 2009)$ until a limiting conversion between 70 and $80 \%$, depending on the formulation, was reached.

It can be observed in Figure 1 that the NIR model was able to describe correctly the trends of these reactions, including the initial induction time followed by a high reaction rate and the limiting conversion. However, some slight deviations can be observed as in Reaction M 6 (Figure 1 (e) and (f)). In this experiment a disturbance, temperature increase in the last hour of reaction, was applied to the system and the model was able to detect this operational disturbance. Finally, Figure $1(\mathrm{~g})$ and $(\mathrm{h})$ show the results of reaction M 8 during which, after 70 min of reaction, $50 \mathrm{wt} \%$ of the total mass of the reaction medium was fed. Again, in this case the model was able to detect correctly the disturbance.

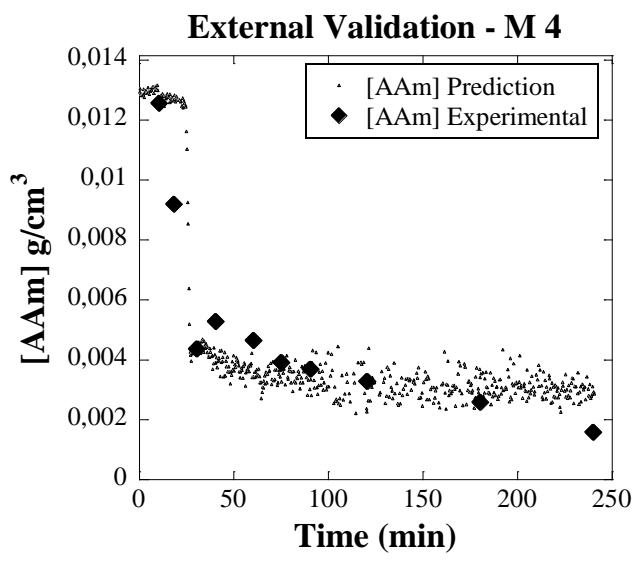

(a)

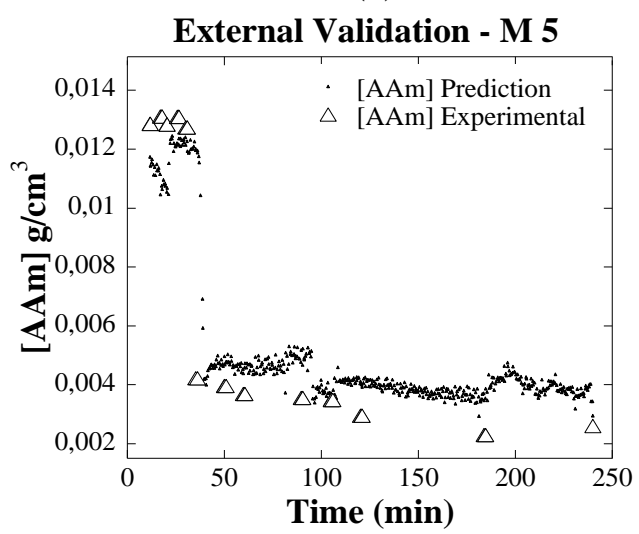

(c)

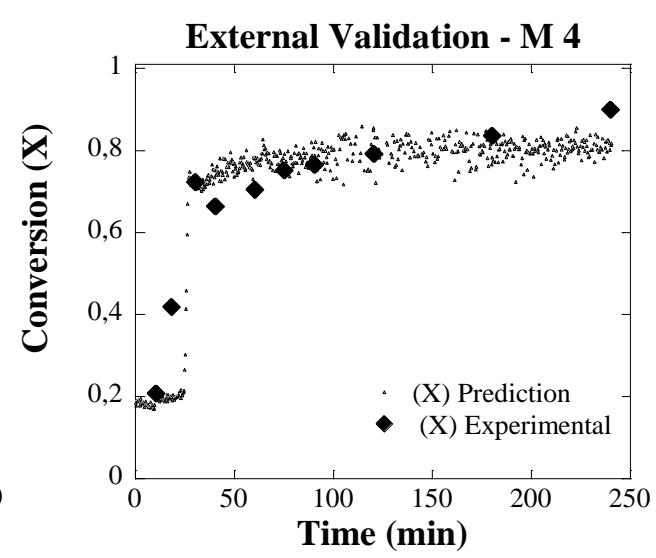

(b)

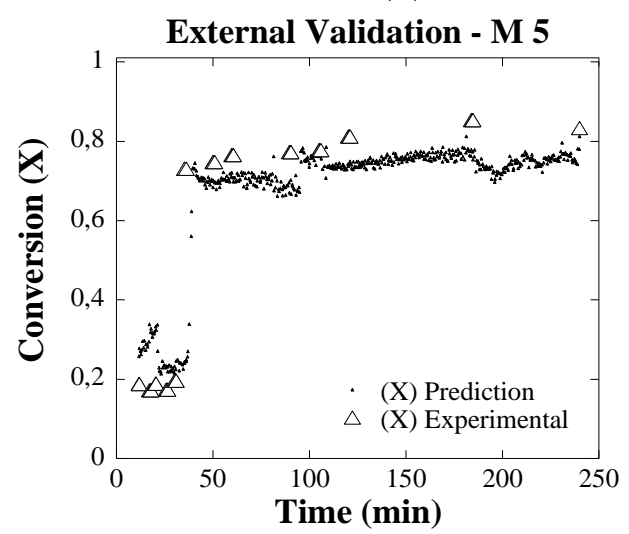

(d) 


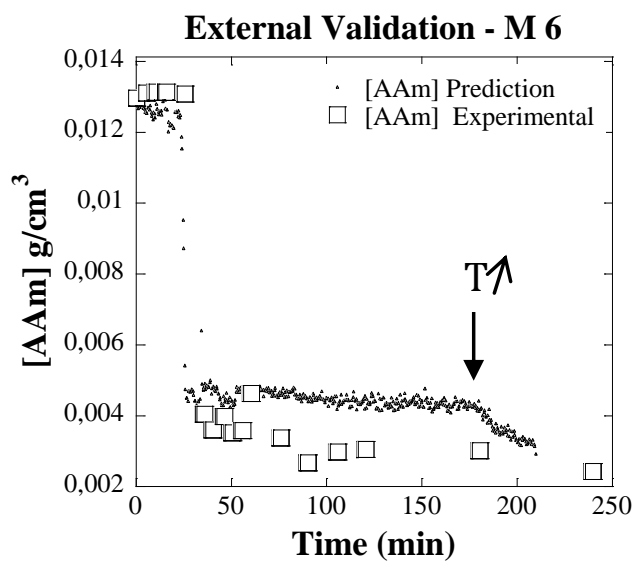

(e)

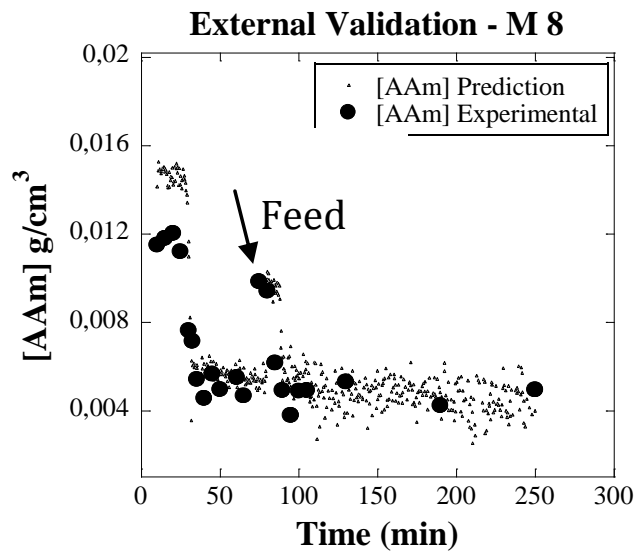

(g)

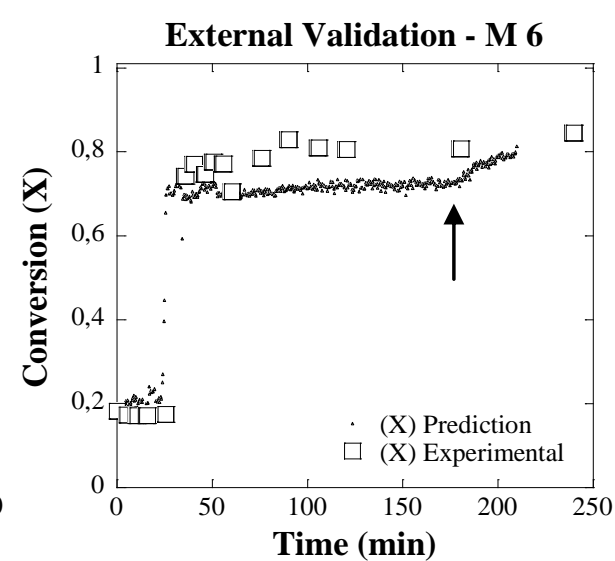

(f)

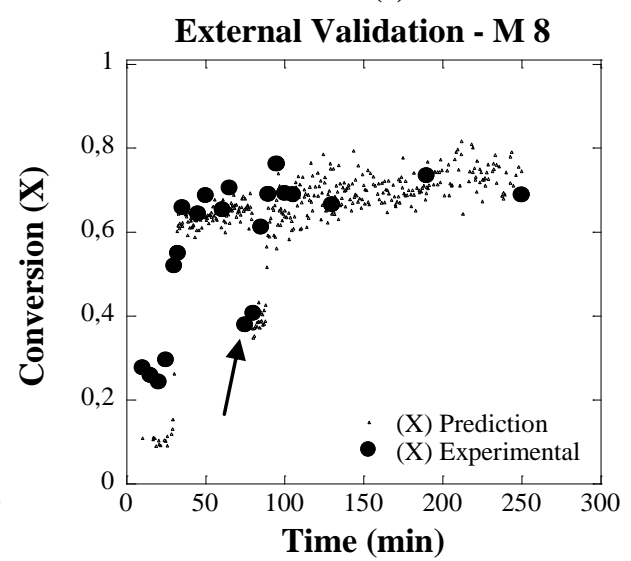

(h)

Figure 1. External validation of the NIR calibration model for the concentration of acrylamide (a), (c), (e), (g), and conversion (b), (d), (f), (h), during polymerizations.

\subsection{NIR model of average particle diameter}

The reaction set for the calibration model of the average particle diameter was selected to cover a wide range of diameters (165 $\mathrm{nm}$ to $250 \mathrm{~nm}$ ), and thus included reactions carried out with both types of surfactants, PGPR (M 1 and M 4) and Span 60 (M 7 and M8). In addition, the spectral region between $9500 \mathrm{~cm}^{-1}$ and $12500 \mathrm{~cm}^{-1}$ was used for the average particle diameter model, (Chicoma et al., 2011). The first derivative with 17 point smoothing with normalization vector was used as spectral pre-processing method. And, based on cross-validation as internal validation, a PLS model with three principal components with $\mathrm{R}^{2}=76$ and $\mathrm{RMSECV}=14.4$ was chosen.

Figure 2 shows the NIR model estimations agreed satisfactorily with Dp data determined offline by DLS, predicting correctly the timing of the abrupt particle size decrease observed for these reactions at around $30 \mathrm{~min}$. The timing of this particle size decrease also agrees with the sharp increase in reaction rate (Figure 1) indicating that possibly another particle nucleation mechanism, besides the desired droplet nucleation, is also active at this point. While the NIR model was able to 
detect correctly the timing of this particle size decrease, it underestimated its magnitude as observed in the small deviations between NIR and DLS Dp values after $30 \mathrm{~min}$ of reaction. During the course of reactions M 2 and M 3, for which after $50 \mathrm{~min}$ of reaction particle size increased from $180 \mathrm{~nm}$ to $200 \mathrm{~nm}$ indicating particle coalescence, several smaller discontinuities may be observed in the Dp values predicted by the NIR model, in addition to the initial abrupt decrease also observed in DLS data. This interference of the formation of aggregates in the NIR spectra, and thus in the estimation of $\mathrm{Dp}$, may be used advantageously for the early detection of the formation these aggregates during the process.

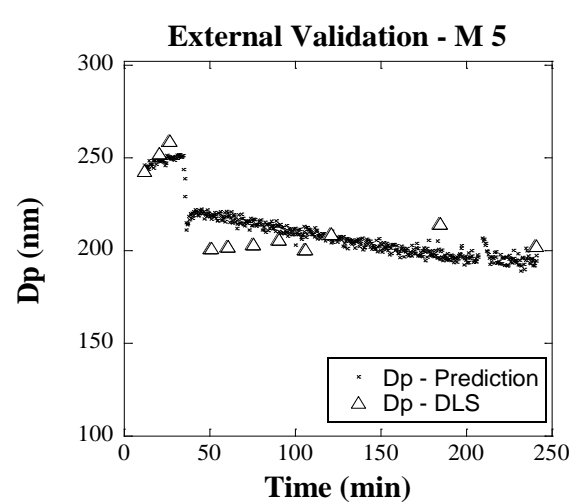

(a)

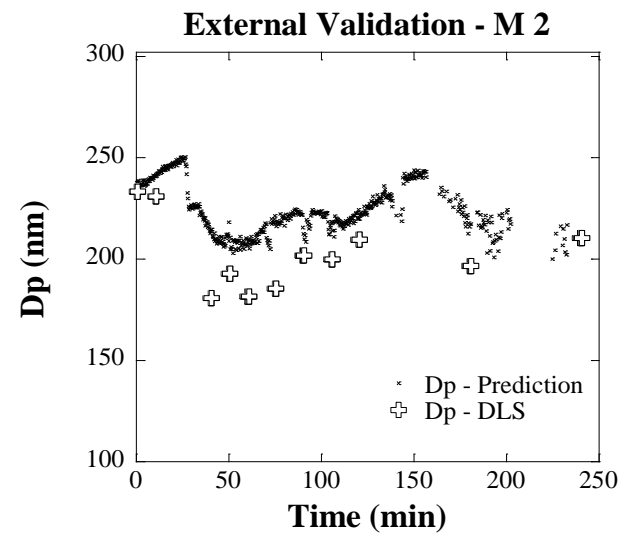

(c)

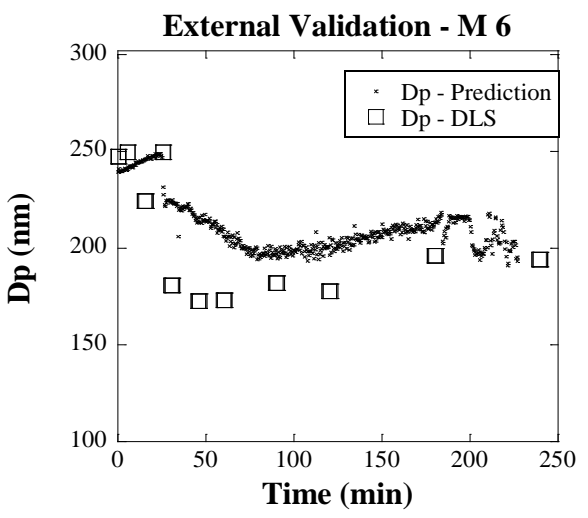

(b)

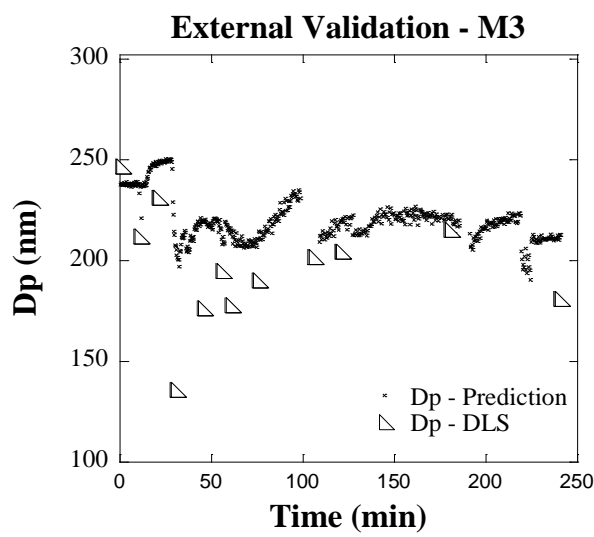

(d)

Figure 2. External validation of the NIR calibration model for the average particle diameter.

\section{CONCLUSIONS}

Results showed the feasibility of on-line monitoring conversion and average particle size in these type of technique using NIR spectroscopy. Using 25-point second derivative with smoothing as spectral pretreatment it was possible to develop a partial least squares calibration model for acrylamide concentration with a high determination coefficient. And external validation of acrylamide concentration and conversion predictions based on on-line NIR spectra showed a good agreement with off-line gravimetric data, keeping track of reaction trends as initial induction time, followed by a very sharp increase of reaction rate. Furthermore, NIR spectroscopy was able to detect disturbances 
such as additional reactant feeding and reaction temperature increase, allowing the possibility of acting on the system. The sensitivity of NIR spectroscopy was able to detect the changes of the diameter particle, also the estimation of complex phenomena like particle nucleation and coalescence.

Acknowledgment - The authors thank the financial support from CAPES (Coordenação de Aperfeiçoamento de Pessoal de Nível Superior) and CNPq (Conselho Nacional de Desenvolvimento Científico e Tecnológico).

\section{REFERENCES}

BLAGODATSKIKH, I.; TIKHONOV, V.; IVANOVA, E.; LANDFESTER, K.; KHOKHLOV, A. New Approach to the Synthesis of Polyacrylamide in Miniemulsified Systems. Macromol. Rapid Commun. v. 27, p $1900-1905,2006$.

CAPEK, I. The inverse mini-emulsion polymerization of acrylamide. Design. Monom. Polym., v. 6, p. $399-409,2003$.

CAPEK, I. On the Inverse Miniemulsion Copolymerization and Terpolymerization of Acrylamide, N, N'- methylenebis (acrylamide) and Methacrylic Acid. Central Europ. J. Chem., v. 3, p. $291-304,2003$.

CAPEK, I. On Inverse Miniemulsion Polymerization of Conventional Water - Soluble Monomers. Adv. Colloid. Interf. Sci., v. 156, p 35-61, 2010.

CHICOMA, D.L. Monitoramento em Linha de Reações de Copolimerização em Emulsão de Acetato de Vinila e Acrilato de Butila em um Reator Contínuo Pulsado de Pratos Perfurados usando Espectroscopia NIR. 2009. 233p. Tese de Doutorado. Engenharia Química, Universidade de São Paulo, São Paulo, 2009.

CHICOMA, D., CARRANZA, V., SAYER, C., GIUDICI, R. In Line Monitoring of VAc-BuA Emulsion Polymerization Reaction in a Continuous Pulsed Sieve Plate Reactor using NIR Spectroscopy. Macromol. Symp. v. 289, p 140-148, 2010.

CHICOMA, D., SAYER, C., GIUDICI, R. In-Line Monitoring of Particle Size during Emulsion Polymerization under Different Operational Conditions using NIR Spectroscopy. Macromol. React. Eng. v. 5, p 150-162, 2011.

KOBITSKAYA, E.; EKINCI, D.; MANZKE, A.; PLETTL, A.; WIEDWALD, U.; ZIEMANN,P.; BISKUPEK, J.; KAISER, U.; ZIENER, U.; LANDFESTER, K. Narrowly Size Distributed Zinc-Containing Poly(acrylamide) Latexes via Inverse Miniemulsion Polymerization. Macromolecules, 43, p 3294-3305, 2010.

LANDFESTER, K.; WILlERT, M.; ANTONIETTI, M. Preparation of Polymer Particles in Nonaqueous Direct and Inverse Miniemulsions. Macromolecules, 33, p 2370 - 2376, 2000. 
LOVELl, P. A., EL-ASSER, M. S. Emulsion Polymerization and Emulsion Polymers. Chichester: J. Wiley 1997.

PATNAIK; PRADYOT. Dean's Analytical Chemistry Handbook. 2nd Edition. McGraw-Hill. p 11432004.

QI, G.; JONES C. W.; SCHORK, F. J. RAFT Inverse Miniemulsion Polymerization of Acrylamide. Macromol. Rapid Commun. v. 28, p 1010-1016, 2007.

QI, G.; ELEAZER, B.; JONES, C.W.; SCHORK, F.J. Mechanistic Aspects of Sterically Stabilized Controlled Radical Inverse Miniemulsion Polymerization. Macromolecules, v. 42, $\mathrm{p}$ $3906-3916,2009$.

REIS, M.M.; ARAÚJO, P.H.H.; SAYER, C.;GIUDICI, R. In Situ Near-Infrared Spectroscopy for Simultaneous Monitoring of Multiple Process Variables in Emulsion Copolymerization. Ind. Eng. Chem. Res., v. 43, p 7243-7250, 2004b.

REIS, M.M.; ULIANA, M.; SAYER, C.; ARAÚJO, P.H.H.; GIUDICI, R. Monitoring Emulsion Homopolimerization Reactions Using FT-RAMAN Spectroscopy. Brazilian J. Chem. Eng., v. 22, p 61-74, 2005.

REIS, M.M.; ARAÚJO, P.H.H.; SAYER, C.; GIUDICI, R.; Spectroscopic on-line monitoring for dispersed medium reactions: Chemometric Challenges, ANALYTICA CHIMICA ACTA, v. 595(1-2), 257-265, 2007.

ROMIO, A.P.; RODRIGUES, H.H.; PERES, A.; DA CAS VIEGAS, A.; KOBITSKAYA, E.; ZIENER, U.; LANDFESTER, K.; SAYER, C.; ARAÚJO, P.H.H. Encapsulation of magnetic nickel nanoparticles via inverse miniemulsion polymerization. J. Appl. Polym. Sci., p 1426- 1433 2013.

SANTOS, A.F.; SILVA, F.M.; LENZI, M.K.; PINTO, J.C.; Monitoring and Control of Polymerization Reactors Using NIR Spectroscopy, Polymer - Plastics Technology and Engineering, v. 44:1, p.1-61, 2005.

SILVA, W.K.; CHICOMA, D.; GIUDICI, R.; In-situ real-time monitoring of particle size, polymer and monomer contents in emulsion polymerization of methyl methacrylate by near infrared spectroscopy, Polymer Engineering and Science, v. 51, 2024-2034, 2011.

ULLMAN'S ENCYCLOPEDIA OF INDUSTRIAL CHEMISTRY, Sixth Edition, Wiley-VCH, p, 8190, 2000.

VIEIRA, R.A.M.; SAYER, C.; LIMA, E.L.; PINTO, J.C. In-Line and In Situ Monitoring of Semi-Batch Emulsion Copolymerizations Using Near-Infrared Spectroscopy, J. Appl. Polym. Sci.,v. 84, p. 2670-2682 (2002). 